\title{
Inhibition of SNCG suppresses the proliferation of lung cancer cells induced by high glucose
}

\author{
JING FEI $^{1}$, CHI XIAO ${ }^{2}$, MEIYING YANG ${ }^{2}$, XUE ZHOU $^{2}$ and PING GONG ${ }^{1}$ \\ ${ }^{1}$ Department of Oncology, The First Affiliated Hospital, Shihezi University School of Medicine, Shihezi, Xinjiang 832000; \\ ${ }^{2}$ Department of Clinical Medicine, Shihezi University School of Medicine, Shihezi, Xinjiang 832000, P.R. China
}

Received July 19, 2020; Accepted November 13, 2020

DOI: $10.3892 / \mathrm{mmr} .2020 .11777$

\begin{abstract}
Lung cancer is the most common cancer type worldwide and the leading cause of cancer-related mortality. Diabetes is closely associated with the occurrence, development and prognosis of lung cancer. Therefore, the present study aimed to investigate whether SNCG could affect the proliferation of lung cancer cells induced by high glucose. Lung cancer cells induced by high glucose simulated the pathologies of patients with lung cancer with diabetes in vitro. The proliferation of $\mathrm{HBE}$ cells and lung cancer cells after transfection and treatment of glucose was detected using Cell Counting Kit-8 assay. The mRNA expression levels of synuclein $\gamma$ (SNCG), insulinlike growth factor 1 (IGF-1) and IGF-1 receptor (IGF-1R) in HBE cells and lung cancer cells alone, or cells induced by high glucose were analyzed via reverse transcription-quantitative (RT-q)PCR analysis. Moreover RT-qPCR analysis was used to determine the transfection efficiencies. The clone formation ability, migration and inflammation of lung cancer cells after high glucose induction and transfection were detected using clone formation, wound healing and ELISA assays. The protein expression levels of SNCG, IGF-1, IGF-1R, ERK 1/2, phosphorylated (p)-ERK1/2 and JNK in lung cancer cells after high glucose induction and transfection were determined using western blot analysis. The results suggested that high glucose significantly promoted the proliferation of A549, NCI-H1975 and SK-MES-1 cells at 24 and $48 \mathrm{~h}$, as well as upregulated the expression levels of SNCG, IGF-1 and IGF-1R. Knockdown of SNCG suppressed the proliferation, clone formation ability and migration, but alleviated inflammation in A549 cells induced by high glucose. Knockdown of SNCG suppressed the expression levels of SNCG, IGF-1, IGF-1R, ERK1/2 and
\end{abstract}

Correspondence to: Dr Ping Gong, Department of Oncology, The First Affiliated Hospital, Shihezi University School of Medicine, 107 North Second Road, Shihezi, Xinjiang 832000, P.R. China E-mail: ggping00@126.com

Key words: synuclein $\gamma$, proliferation, lung cancer cells, high glucose
p-ERK1/2, while it promoted JNK expression in A549 cells induced by high glucose. The effect of AXL1717 (an IGF-1R inhibitor) treatment on cells was consistent with that of SNCG knockdown. In conclusion, inhibition of SNCG suppresses proliferation of lung cancer cells induced by high glucose.

\section{Introduction}

With the development of medical technology, there has been increased early prevention and diagnosis of cancer, improved awareness of cancer prevention and significantly reduced cancer mortality worldwide. Over the past 20 years, the number of cancer-related mortalities has decreased by $\sim 2.4$ million ((1). However, lung cancer remains the number one cause of mortality by cancer (2). The 5-year survival rate of patients with lung cancer is only $18 \%$, and early diagnosis of lung cancer can decrease the mortality rate by 10-50 times. However, most patients with lung cancer are diagnosed at an advanced stage (3).

According to the 2017 Global Diabetes Map (8th edition), 425 million adults (20-79 years) worldwide suffer from diabetes, with China accounting for 114.4 million cases, ranking first in the world (4). Several studies have reported that diabetes is a risk factor for lung cancer and leads to poor prognosis (5-7). Therefore, it is important to identify effective methods to treat patients with lung cancer with diabetes.

The synuclein $\gamma$ (SNCG) gene encodes the $\gamma$-synuclein protein that is considered to be the third member of the synuclein family ( $\alpha, \beta$ and $\gamma$ ), which are reported to be involved in the pathogenesis of neurodegenerative diseases. SNCG is also known as breast cancer specific gene 1, and is highly expressed in advanced breast cancer tissues (8). In recent years, studies have revealed that SNCG expression is abnormally high in breast $(9,10)$, esophageal (11), colorectal (12), bladder (13), ovarian (9), lung cancer (14) and other malignant tumors. Moreover, there is close association between SNCG expression and development of malignant tumors. A study (15) has shown that SNCG and insulin-like growth factor 1 (IGF-1) receptor (IGF-1R) are mutually regulated in various types of tumors, such as breast, hepatoma, colon cancer and lung cancer. Inhibition of SNCG may inhibit IGF-1/IGF-1R-induced cell proliferation and migration; furthermore, IGF-1R inhibitors can block the abnormal expression of SNCG in cancer cells (15). 
IGF-1 and IGF-1R are important growth factors in the body. IGF-1 can be expressed in all parts of the body, while it is mainly synthesized and secreted by the liver and exerts an insulin-like effect on tissue cells (16). IGF-1R, which is highly expressed in most human tumor tissues, can promote the growth and proliferation, while inhibit the apoptosis of tumor cells (17). Most diabetic patients are accompanied by hyperinsulinemia, with a certain level of IGF-binding protein inhibition and relatively increased levels of free IGF-1 (18). Moreover, IGF-1 is highly expressed in lung, colorectal, breast, prostate cancer and other cancer types, which promotes the binding of IGF-1 and IGF-1R, thereby activating the IGF-1/IGF-1R signaling pathway to promote the development of tumors (19).

Therefore, the present study aimed to investigate whether SNCG could affect the proliferation of lung cancer cells induced by high glucose. The results may provide further background for the treatment of lung cancer, especially for patients with lung cancer with diabetes.

\section{Materials and methods}

Cell culture and high glucose induction. Lung cancer cell lines (A549, NCI-H1975 and SK-MES-1 cells) were obtained from the American Type Culture Collection. HBE cells were purchased from Procell Life Science \& Technology Co., Ltd. HBE cells and lung cancer cell lines were cultured in RPMI-1640 medium (Thermo Fisher Scientific, Inc.) containing 10\% FBS (Gibco; Thermo Fisher Scientific, Inc.) and $1 \%$ penicillin in $5 \% \mathrm{CO}_{2}$ at $37^{\circ} \mathrm{C}$. $\mathrm{HBE}$ cells and lung cancer cells were treated with $5.5 \mathrm{mM}$ glucose (Beyotime Institute of Biotechnology) and $25 \mathrm{mM}$ glucose at $37^{\circ} \mathrm{C}$ for 24 and $48 \mathrm{~h}$. The glucose concentrations were determined according to previous studies $(20,21)$.

Cell transfection. Small interfering (si) RNA-SNCG was purchased from Shanghai GeneChem Co., Ltd. siRNASNCG-\#1 forward, 5'-GAAUGUUGUACAGAGCGUTT-3' and reverse, 5'-CACGCUCUGUACAACAUUCTC-3'. siRNASNCG-\#2 forward, 5'-CCUCUGCCUUGGACACCAUTT-3' and reverse, 5'-AUGGUGUCCAAGGCAGAGGAG-3'. siRNA NC forward, 5'-UUCUCCGAACGUGUCACGUTT-3' and reverse, 5'-CUUGAGGCUGUUGUCAUACTT-3'. According to the Lipofectamine ${ }^{\circledR} 2000$ specification, lung cancer cells were transfected with siRNA NC (5 nM), siRNA1 (5 nM) and siRNA $2(5 \mathrm{nM})$ at $37^{\circ} \mathrm{C}$ for $24 \mathrm{~h}$ and the cell adherence reached $\sim 50 \%$ for transfection using Lipofectamine ${ }^{\circledR} 2000$ (Invitrogen; Thermo Fisher Scientific, Inc.). Subsequent experiments were performed $24 \mathrm{~h}$ after transfection.

Cell Counting Kit-8 (CCK-8) assay. HBE cells and lung cancer cells were seeded into 96 -well plates $\left(1 \times 10^{4}\right.$ cells/well) and respectively treated with $5.5 \mathrm{mM}$ glucose and $25 \mathrm{mM}$ glucose at $37^{\circ} \mathrm{C}$ for $24 \mathrm{~h}$ and $48 \mathrm{~h}$. A549 cells respectively transfected with siRNA NC and siRNA-SNCG were treated with $25 \mathrm{mM}$ glucose, and A549 cells were treated with AXL1717 $(10 \mu \mathrm{M}$; MedChemExpress) and $25 \mathrm{mM}$ glucose at $37^{\circ} \mathrm{C}$ for 24 and $48 \mathrm{~h}$. According to the manufacturer's instructions, $10 \mu \mathrm{l}$ CCK-8 solution (Beyotime Institute of Biotechnology) was added to each well, which was incubated at $37^{\circ} \mathrm{C}$ for $4 \mathrm{~h}$.
The absorbance at a wavelength of $450 \mathrm{~nm}$ for each well was detected using a ThermoMax microplate reader (Thermo Fisher Scientific, Inc.) in the dark.

Reverse transcription-quantitative PCR (RT-qPCR). Following the indicated treatments, TRIzol ${ }^{\circledR}$ reagent (Thermo Fisher Scientific, Inc.) was used to extract total RNA from lung cancer cells. cDNA was synthesized using the Transcriptor First Strand cDNA Synthesis kit (Roche Molecular Diagnostics) at $42^{\circ} \mathrm{C}$ for $30 \mathrm{~min}$. The expression levels of SNCG, IGF-1 and IGF-1R were determined using the SYBR-Green Real-Time PCR kit (Beyotime Institute of Biotechnology). The thermocycling conditions were: $95^{\circ} \mathrm{C}$ for $25 \mathrm{sec}, 95^{\circ} \mathrm{C}$ for $15 \mathrm{sec}, 60^{\circ} \mathrm{C}$ for $25 \mathrm{sec}, 72^{\circ} \mathrm{C}$ for $25 \mathrm{sec}$ (35 cycles). The primer sequences were as follows: SNCG forward, 5'-ATGGATGTCTTCAAGAAGGG-3' and reverse, 5'-CTCTGTACAACATTCTCCTT-3'; IGF-1 forward, 5'-ACGCTCT TCAGTTCGTGTGT-3' and reverse, 5'-CTTCAGCGGAGCACAGTACA-3'; IGF-1R forward, 5'-GGTGTCCAATAACTACATTG-3' and reverse, 5'-CAGCGGTTTGTGGTCCAGC-3'; and GAPDH forward, 5'-GAAGGTGAAGGTCGGAGT-3' and reverse, 5'-GAAGATGGTGATGGGATT-3'. The relative expression levels of SNCG, IGF-1 and IGF-1R were calculated using the $2^{-\Delta \Delta \mathrm{Cq}}$ method with GAPDH as a reference gene (22).

Clone formation assay. Following the indicated treatments, lung cancer cells were inoculated into a 6 -well plate at a density of $1 \times 10^{5}$ cells/well. The cells were placed in a $37^{\circ} \mathrm{C}$ cell incubator for culture. The medium was changed once for 2-3 days. After 15 days, the cells were washed with PBS three times, fixed with $4 \%$ formaldehyde for $30 \mathrm{~min}$ at room temperature, stained with crystal violet for $20 \mathrm{~min}$ at room temperature, washed with PBS and observed under a light microscope after drying (magnification, x100).

Wound healing assay. A549 cells were seeded in 6-well plates and A549 cells were treated with $5.5 \mathrm{mM}$ glucose and $25 \mathrm{mM}$ glucose for $48 \mathrm{~h}$. A549 cells respectively transfected with siRNA NC and siRNA-SNCG were treated with $25 \mathrm{mM}$ glucose, and A549 cells were treated with AXL1717 $(10 \mu \mathrm{M}$; MedChemExpress) and $25 \mathrm{mM}$ glucose at $37^{\circ} \mathrm{C}$ for $48 \mathrm{~h}$. Once the cells were adherent, a scratch was made using a 200- $\mu 1$ sterile pipette tip. Serum-free RPMI-1640 medium was then added for further culture for $24 \mathrm{~h}$, and wound healing was observed and photographed under a light microscope magnification, x100) $24 \mathrm{~h}$ after the scratch was made. The online image analysis system of WimScratch (Wimasis; https://www.wimasis.com/en/) used to measure the cell scratch width.

ELISA. Cells were cultured after the indicated treatments for $24 \mathrm{~h}$ and the cell supernatant was collected after centrifugation $(3,000 \mathrm{x} \mathrm{g})$ at $4^{\circ} \mathrm{C}$ for $15 \mathrm{~min}$. The levels of TNF- $\alpha$ and IL-6 in cell supernatant were detected using respective TNF- $\alpha$ (PT518) and IL-6 (PI330) ELISA kits (Beyotime Institute of Biotechnology) according to the manufacturer's instructions.

Western blot analysis. Following the indicated treatments, lung cancer cells were lysed with cell lysis buffer (Beyotime 
Institute of Biotechnology) and an ultrasonic cell disruptor. The cells were centrifuged at $3,000 \mathrm{x} \mathrm{g}$ at $4^{\circ} \mathrm{C}$ for $15 \mathrm{~min}$ and the supernatant was obtained. Protein concentration was quantified using the protein concentration determination kit (Bio-Rad Laboratories, Inc.). A total of $20 \mu \mathrm{g}$ protein/lane was separated using 10\% SDS-PAGE. Separated proteins were transferred to a PVDF membrane at $100 \mathrm{~V}$ and blocked with $5 \%$ skim milk powder for $2 \mathrm{~h}$ at room temperature. Subsequently, membranes were incubated with SNCG (cat. no. ab52633; 1:1,000; Abcam), IGF-1 (cat. no. ab133542; 1:1,000; Abcam), IGF-1R (cat. no. ab182408; 1:1,000; Abcam), ERK1/2 (cat. no. ab184699; 1:10,000; Abcam), phosphorylated (p)-ERK1/2 (cat. no. ab223500; 1:400; Abcam), c-JNK (cat. no. ab199380; 1:2,500; Abcam) and GAPDH (cat. no. ab8245; 1:1,000; Abcam) antibodies at $4^{\circ} \mathrm{C}$ overnight. Following three washes with TBS-Tween-20 (0.05\%), the membranes were then incubated with horseradish peroxidase-conjugated secondary antibody (cat. no. 7074; 1:1,000; Cell Signaling Technology, Inc.) at $25^{\circ} \mathrm{C}$ for $1 \mathrm{~h}$. Protein bands were visualized using an enhanced chemiluminescence system (Bio-Rad Clarity Western EC; Bio-Rad Laboratories, Inc.). Relative protein expression was quantified using Image-Pro Plus software (version 6.0; Media Cybernetics, Inc.)

Statistical analysis. All experiments were repeated three times, and experimental data are presented as the mean \pm SD. SPSS 22.0 (IBM Corp.) was used for statistical analysis of all data, and GraphPad Prism 6 (GraphPad Software, Inc.) was used for mapping. One-way ANOVA with Tukey's post hoc test was used for the comparison of mean values between groups. $\mathrm{P}<0.05$ was considered to indicate a statistically significant difference.

\section{Results}

Proliferation of lung cancer cells increases after high glucose induction. After HBE cells and lung cancer cells were treated with $5.5 \mathrm{mM}$ glucose, the proliferation of A549 and NCI-H1975 cells was increased, while SK-MES-1 cell proliferation was not significantly different compared with HBE cells at $24 \mathrm{~h}$. The proliferation of A549, NCI-H1975 and SK-MES-1 cells was significantly increased compared with HBE cells at $48 \mathrm{~h}$ (Fig. 1A). As presented in Fig. 1B, treatment of $25 \mathrm{mM}$ glucose significantly increased the proliferation of A549, NCI-H1975 and SK-MES-1 cells compared with HBE cells at 24 and $48 \mathrm{~h}$.

Expression levels of SNCG, IGF-1 and IGF-1R in lung cancer cells increase after high glucose induction. SNCG expression was increased in A549 and NCI-H1975 cells, while it was decreased in SK-MES-1 cells. IGF-1 expression was decreased and that of IGF-1R was increased in A549, NCI-H1975 and SK-MES-1 cells. The trend of SNCG, IGF-1 and IGF-1R expression levels was different in lung cancer cells compared with HBE cells (Fig. 2A). Following treatment of lung cancer cells with high glucose $(25 \mathrm{mM})$, the expression levels of SNCG, IGF-1 and IGF-1R in lung cancer cells were increased compared with HBE cells; SNCG, IGF-1 and IGF-1R expression levels were highest in A549 cells (Fig. 2B). Therefore, A549 cells were chosen for subsequent experiments.
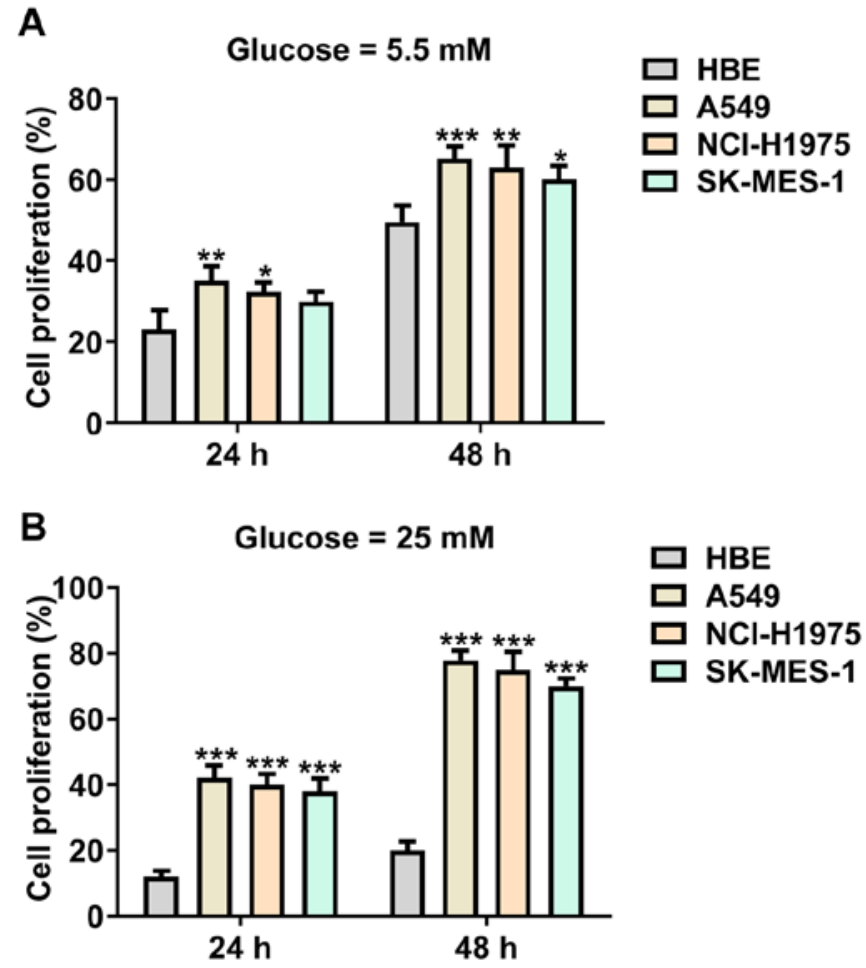

Figure 1. Proliferation of lung cancer cells is increased after high glucose induction. (A) Proliferation of $\mathrm{HBE}$ cells and lung cancer cells treated with normal glucose was detected using a CCK-8 assay. (B) Proliferation of HBE cells and lung cancer cells treated with high glucose was detected via a CCK-8 assay. ${ }^{*} \mathrm{P}<0.05,{ }^{* *} \mathrm{P}<0.01$ and ${ }^{* * *} \mathrm{P}<0.001$ vs. HBE group. CCK-8, Cell Counting Kit-8.

Knockdown of SNCG suppresses the proliferation and clone formation ability of lung cancer cells. Following transfection of A549 cells with siRNA negative control (NC), siRNA-SNCG-\#1 and siRNA-SNCG-\#2, SNCG expression was downregulated in cells transfected with siRNA-SNCG-\#1 or siRNA-SNCG-\#2, while its expression did not significantly change in cells transfected with siRNA NC. SNCG expression in A549 cells transfected with siRNA-SNCG-\#1 was the lowest; hence, siRNA-SNCG-\#1 was selected for subsequent experiments (Fig. 3A). After A549 cells were treated with high glucose (25 mM), A549 cell proliferation was enhanced, which was not significantly affected by siRNA NC transfection. Knockdown of SNCG suppressed the proliferation of A549 cells, and the same effects were observed following AXL1717 treatment (Fig. 3B). The results of the clone formation assay indicated that the trend of clone formation ability of A549 cells in each group was consistent with the trend of A549 cell proliferation (Fig. 3C).

Knockdown of SNCG suppresses the migration of lung cancer cells induced by high glucose. As presented in Fig. 4, high glucose $(25 \mathrm{mM})$ treatment enhanced A549 cell migration, an increase which was not affected when high glucose (25 mM)-induced A549 cells were transfected with siRNA NC. However, knockdown of SNCG suppressed the migration of high glucose (25 mM)-induced A549 cells, and the same effects were observed following AXL1717 treatment. AXL1717 treatment appeared to exhibit a significantly greater 

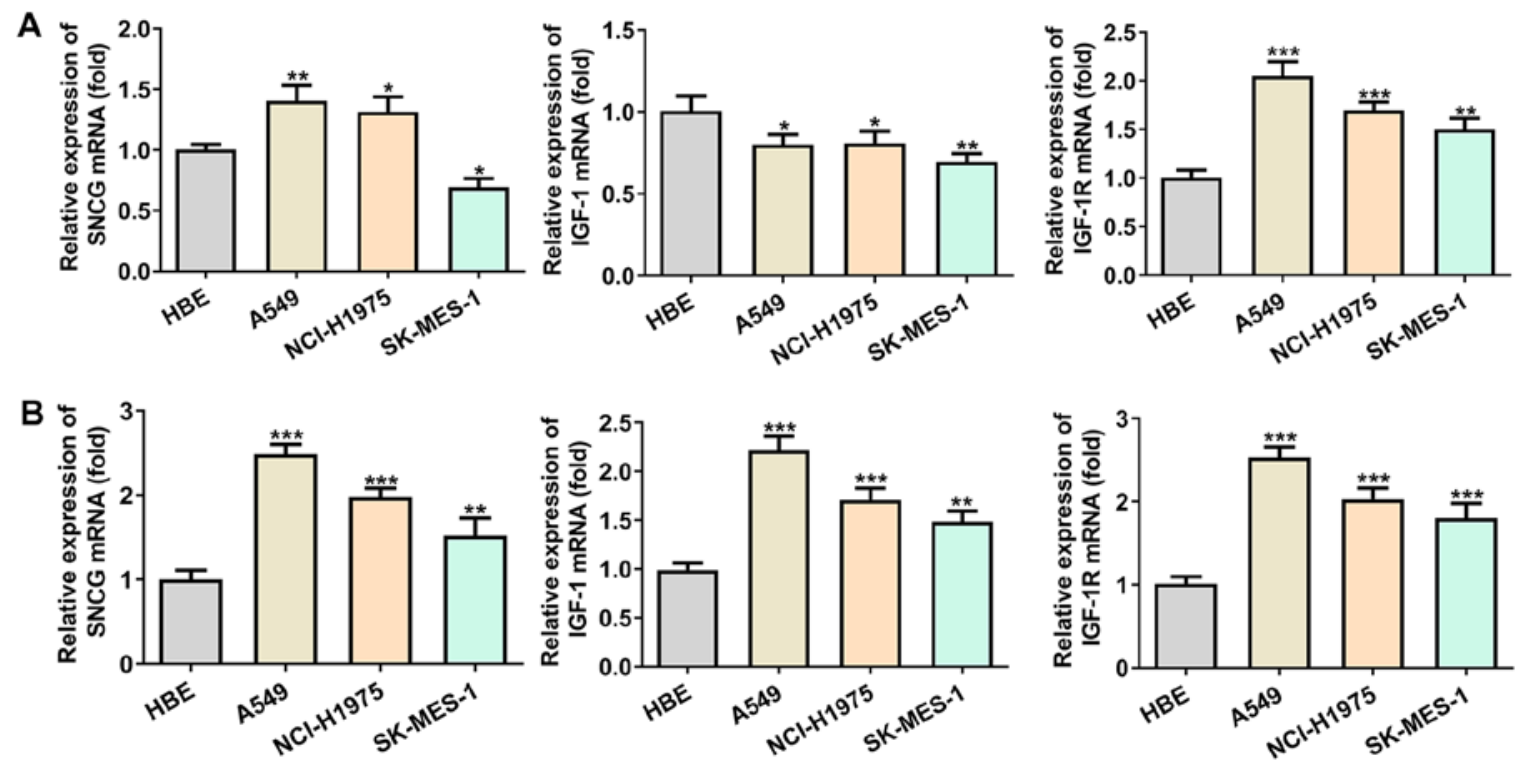

Figure 2. Expression levels of SNCG, IGF-1 and IGF-1R in lung cancer cells are increased after high glucose induction. (A) Expression levels of SNCG, IGF-1 and IGF-1R in HBE cells and lung cancer cells were determined via RT-qPCR analysis. (B) Expression of SNCG, IGF-1 and IGF-1R in HBE cells and lung cancer cells all treated with high glucose $(25 \mathrm{mM})$ were determined using RT-qPCR analysis. ${ }^{*} \mathrm{P}<0.05,{ }^{* *} \mathrm{P}<0.01$ and ${ }^{* * * *} \mathrm{P}<0.001$ vs. HBE group. RT-qPCR, reverse transcription-quantitative PCR; SNCG, synuclein $\gamma$; IGF-1, insulin-like growth factor 1; IGF-1R, IGF-1 receptor.
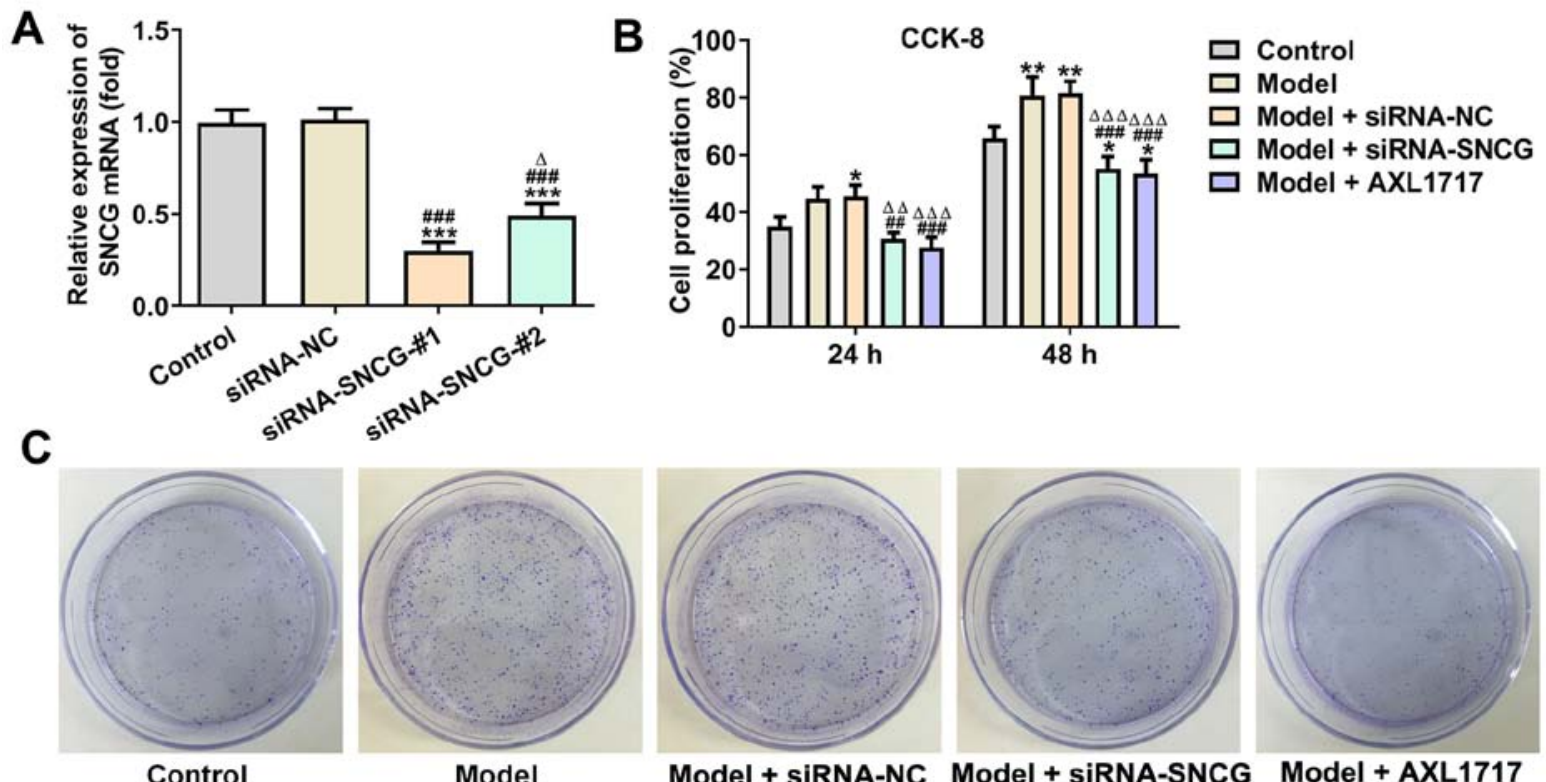

Figure 3. Knockdown of SNCG suppresses the proliferation and clone formation ability of lung cancer cells. (A) Transfection effects of siRNA NC, siRNA-SNCG-\#1 and siRNA-SNCG-\#2 were confirmed via RT-qPCR analysis. ${ }^{* * *} \mathrm{P}<0.001$ vs. Control group; ${ }^{\# \# \#} \mathrm{P}<0.001$ vs. siRNA-NC group; ${ }^{\wedge} \mathrm{P}<0.05$ vs. siRNA-SNCG-\#1 group. (B) Proliferation of A549 cells after indicated treatment was detected using a CCK-8 assay. "P<0.05 and ${ }^{* *} \mathrm{P}<0.01$ vs. Control group; ${ }^{\# \#} \mathrm{P}<0.01$ and ${ }^{\# \# \#} \mathrm{P}<0.001$ vs. Model group; ${ }^{\Delta \Delta} \mathrm{P}<0.01$ and ${ }^{{ }^{\Delta \Delta} \mathrm{P}} \mathrm{P}<0.001$ vs. Model + siRNA-NC group. (C) Clone formation ability of A549 cells after indicated treatment was detected using a clone formation assay. NC, negative control; siRNA, small interfering RNA; SNCG, synuclein $\gamma$; CCK-8, Cell Counting Kit-8.

effect on cell migration compared with siRNA transfection (Fig. 4).

Knockdown of SNCG alleviates inflammation in lung cancer cells induced by high glucose. The levels of TNF- $\alpha$ were significantly elevated in high glucose $(25 \mathrm{mM})$-induced A549 cells, and siRNA NC transfection did not affect the levels of TNF- $\alpha$ in these cells. Knockdown of SNCG and AXL1717 treatment decreased TNF- $\alpha$ levels in high glucose
(25 mM)-induced A549 cells (Fig. 5A). High glucose (25 mM) upregulated the levels of IL-6 in A549 cells and A549 cells transfected with siRNA NC. Moreover, knockdown of SNCG reversed the promotive effects of high glucose $(25 \mathrm{mM})$ on the levels of IL-6, which was similar to AXL1717 treatment (Fig. 5B).

Knockdown of SNCG suppresses the proliferation-associated signaling pathway. High glucose $(25 \mathrm{mM})$ promoted the 


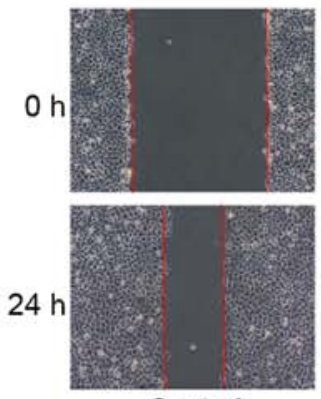

Control

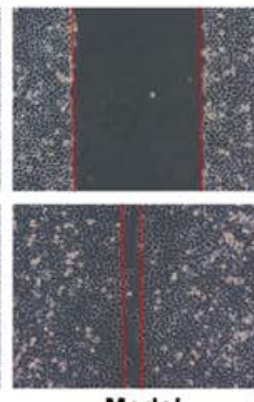

Model
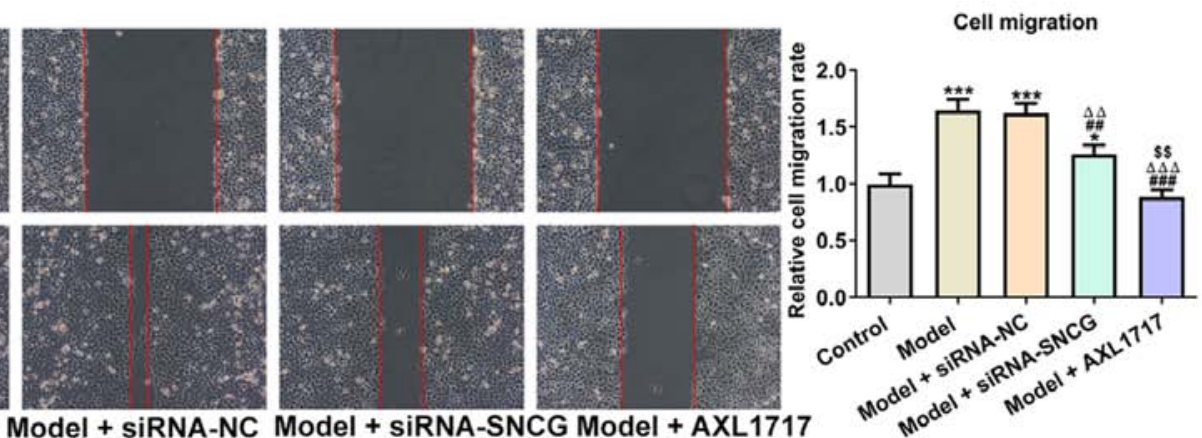

Figure 4. Knockdown of SNCG suppresses the migration of lung cancer cells. The migration of A549 cells after indicated treatment was detected using a wound healing assay (magnification, $\mathrm{x} 100)$. ${ }^{*} \mathrm{P}<0.05$ and ${ }^{* * * *} \mathrm{P}<0.001$ vs. Control group; ${ }^{\# \#} \mathrm{P}<0.01$ and ${ }^{\# \# \#} \mathrm{P}<0.001$ vs. Model group; ${ }^{\Delta \Delta} \mathrm{P}<0.01$ and ${ }^{\Delta \Delta \Delta} \mathrm{P}<0.001$ vs. Model + siRNA-NC group; ${ }^{\$ \$} \mathrm{P}<0.01$ vs. Model + siRNA-SNCG group. NC, negative control; siRNA, small interfering RNA; SNCG, synuclein $\gamma$.
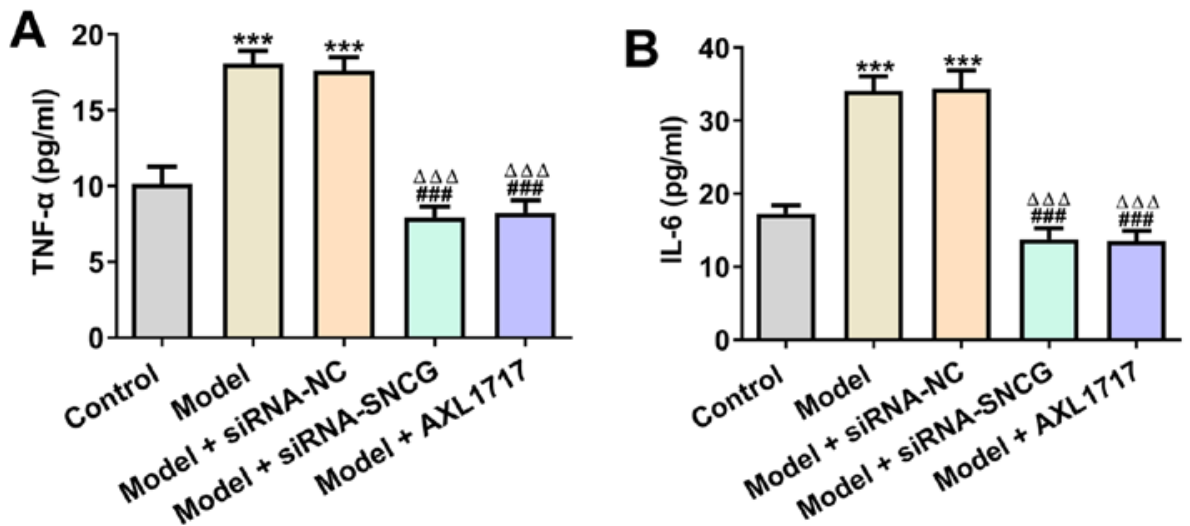

Figure 5. Knockdown of SNCG alleviates the inflammation in lung cancer cells. Levels of (A) TNF- $\alpha$ and (B) IL-6 in supernatant of A549 cells after indicated treatment were detected using the appropriate ELISA kit. ${ }^{* * *} \mathrm{P}<0.001 \mathrm{vs}$. Control group; ${ }^{\# \# \#} \mathrm{P}<0.001$ vs. Model group; ${ }^{\Delta \Delta \Delta} \mathrm{P}<0.001$ vs. Model + siRNA-NC group. NC, negative control; siRNA, small interfering RNA; SNCG, synuclein $\gamma$.

expression levels of SNCG, IGF-1 and IGF-1R, which were not significantly altered after siRNA NC transfection (Fig. 6A). The expression levels of SNCG, IGF-1 and IGF-1R in A549 cells induced by high glucose $(25 \mathrm{mM})$ were decreased after siRNA SNCG transfection or AXL1717 treatment. In addition, the inhibitory effects of siRNA-SNCG transfection on SNCG expression were more significant compared with AXL1717 treatment, while the inhibitory effects of AXL1717 treatment on IGF-1R expression were more significant compared with siRNA-SNCG transfection. As presented in Fig. 6B, high glucose $(25 \mathrm{mM})$ upregulated the expression levels of ERK1/2 and p-ERK1/2, while JNK expression was downregulated in A549 cells. It was identified that knockdown of SNCG suppressed the expression levels of ERK1/2 and p-ERK1/2, but promoted JNK expression in A549 cells induced by high glucose $(25 \mathrm{mM})$. The effects of AXL1717 treatment on the expression levels of ERK1/2, p-ERK1/2 and JNK was consistent with that of SNCG knockdown. AXL1717 treatment appeared to exhibit a significantly greater effect on expression of SNCG, IGF-1R and JNK compared with siRNA transfection.

\section{Discussion}

With the yearly increase of China's aging population and the prevalence of diabetes, the number of patients with lung cancer with diabetes is also rising $(23,24)$. Diabetes can shorten the survival time of patients with lung cancer, especially in patients with non-small cell lung cancer undergoing surgical treatment $(25,26)$. Therefore, additional studies on patients with lung cancer with diabetes should be performed, and further researches on the mechanisms and possible interventions are required.

Insulin raises the levels of free and bioactive IGF-1 in the bloodstream by inhibiting the liver's production of IGF-binding proteins (27). Most human tumor cells have high expression levels of insulin receptors and IGF-1R (28). High concentrations of IGF-1 may increase the risk of multiple epithelial neoplasms (29) and influence the occurrence of breast cancer, endometrial cancer, prostate cancer and other tumors by regulating sex hormones (30). IGF-1 and IGF-1R can also induce the transcription of the VEGF gene, upregulate VEGF expression and enhance the formation of new blood vessels, thereby promoting the occurrence and development of tumors (31). In the present study, the expression levels of IGF-1 and IGF-1R were increased in lung cancer cells induced by high glucose. AXL1717 served as an IGF-1R blocker to suppress SNCG expression in A549 cells induced by high glucose. It was found that AXL1717 treatment suppressed the proliferation, clone formation and migration, as well as alleviated inflammation in A549 cells induced by high glucose. 
A
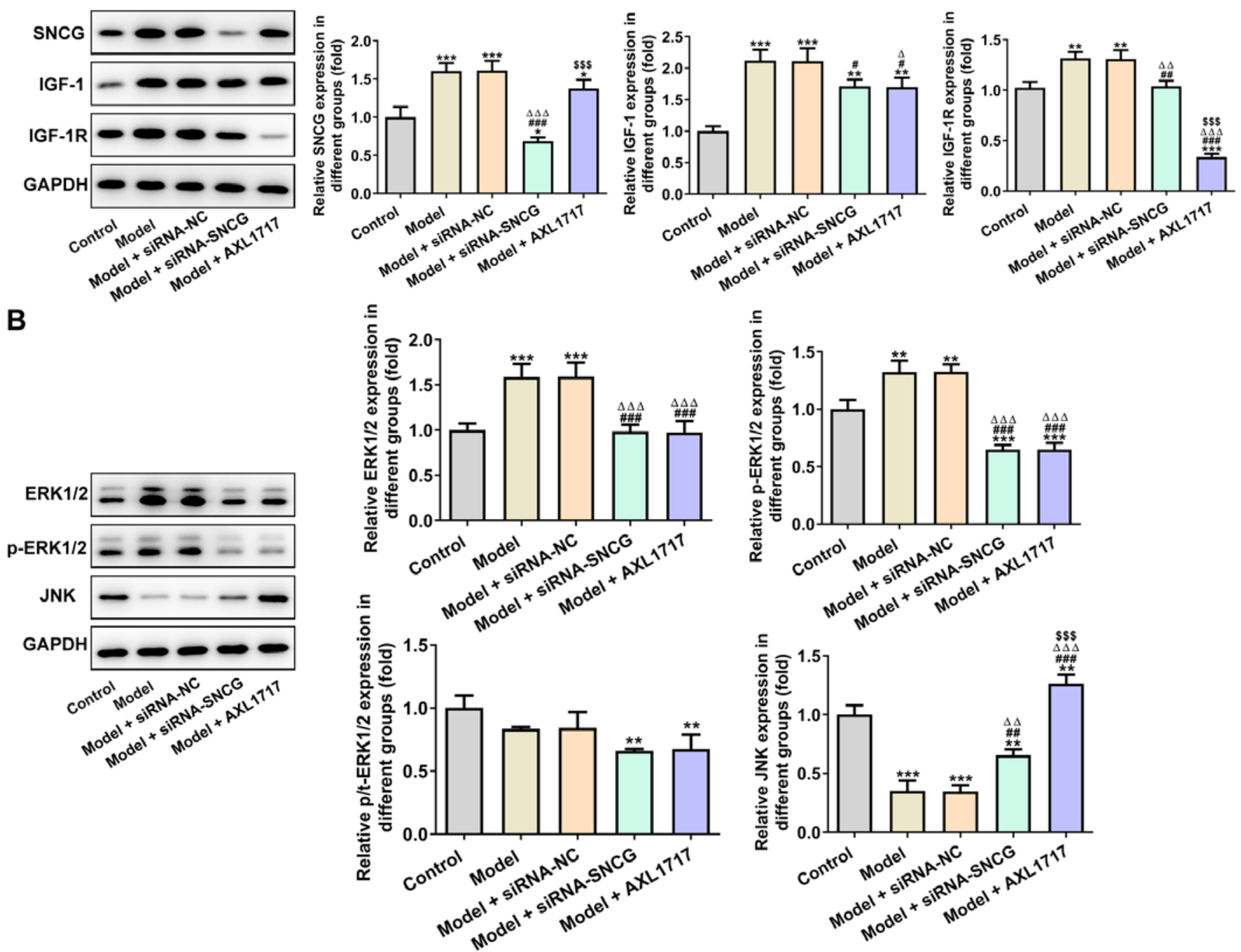

Figure 6. Knockdown of SNCG suppresses the proliferation-related signaling pathway. (A) Expression levels of SNCG, IGF-1 and IGF-1R in A549 cells after indicated treatment were analyzed using western blot analysis. (B) Expression levels of ERK1/2, p-ERK1/2 and JNK in A549 cells after indicated treatment were analyzed via western blot analysis. ${ }^{*} \mathrm{P}<0.05,{ }^{* *} \mathrm{P}<0.01$ and ${ }^{* * *} \mathrm{P}<0.001$ vs. Control group; ${ }^{\#} \mathrm{P}<0.05,{ }^{\# \#} \mathrm{P}<0.01$ and ${ }^{\# \# \#} \mathrm{P}<0.001$ vs. Model group; ${ }^{\Delta \mathrm{P}}<0.05$, ${ }^{\Delta \Delta} \mathrm{P}<0.01$ and ${ }^{\Delta \Delta \Delta} \mathrm{P}<0.001$ vs. Model + siRNA-NC group; ${ }^{\$ \$ \$} \mathrm{P}<0.001$ vs. Model + siRNA-SNCG group. NC, negative control; siRNA, small interfering RNA; SNCG, synuclein $\gamma$; p-, phosphorylated; IGF-1, insulin-like growth factor 1; IGF-1R, IGF-1 receptor; t-, total.

SNCG and IGF-1R are mutually regulated in various types of tumors, including breast, hepatoma, colon and lung cancer (15). Surgucheva et al (32) reported that SNCG overexpression may enhance MMP gene expression by upregulating the MAPK pathway and phosphorylating AP-1, thereby promoting the migration and invasion of tumor cells. SNCG overexpression can stimulate proliferation and induce the metastasis of breast cancer cells (33). Shen et al (34) demonstrated that inhibition of SNCG reduced the colony formation and invasion of breast cancer cells, and downregulation of the SNCG gene could inhibit tumor growth in vivo. In the present study, SNCG knockdown could suppress cell proliferation, clone formation and migration, and alleviated inflammation in A549 cells induced by high glucose.

ERK is a mitogen-transmitting signal transduction protein that participates in signaling pathways associated with proliferation, invasion, migration and apoptosis of a large proportion of tumor cells (35). The ERK/JNK signaling pathway is an important intracellular pathway that regulates proliferation and apoptosis of tumor cells, and its abnormal activation affects proliferation, differentiation and apoptosis (36). Yang et al (37) indicated that ERK overexpression could enhance the proliferation, migration and invasion of A549 cells. Moreover, ERK activates p90-ribosomal S6 kinase to inactivate the apoptotic protein Bad, thereby inhibiting cell apoptosis in lung cancer (38). It has also been reported that microRNA-23a could further inhibit the proliferation and migration of A549 cells by activating the JNK signaling pathway (39). In the present study, the proliferation, clone formation and migration of A549 cells induced by high glucose was decreased when $\mathrm{p}$-ERK1/2 expression was downregulated and JNK expression was increased.

Downregulation of SNCG suppresses the proliferation, migration and tumorigenesis of gastric cancer by inhibiting the phosphorylation of AKT and ERK (40). Low-dose ProEGCG has also been reported to significantly enhance phosphorylation of JNK and p38 MAPK, and inhibit phosphorylation of Akt and ERK in endometrial cancer (41). The change in JNK was opposite to the changes in Akt and ERK in cancer; these 
findings are consistent with the present results. In the present study, knockdown of SNCG suppressed the expression levels of ERK1/2 and p-ERK1/2, while promoted JNK expression in A549 cells induced by high glucose.

In conclusion, the present study demonstrated that SNCG knockdown suppressed the proliferation, clone formation and migration, as well as alleviated inflammation of A549 cells induced by high glucose, which provides a background for the treatment of patients with lung cancer with diabetes. However, there are limitations to the present study. For instance, overexpression experiments were not included in this study and such experiments would strengthen the results of the present study. Moreover, there was no animal model to further investigate the role of SNCG in lung cancer under the condition of high glucose in vivo. These limitations should be resolved in future studies.

\section{Acknowledgements}

Not applicable.

\section{Funding}

No funding was received.

\section{Availability of data and materials}

The datasets used and/or analyzed during the current study are available from the corresponding author on reasonable request.

\section{Authors' contributions}

PG conceived and designed the experiments. JF performed all the experiments with the help of CX and MY, and analyzed the experimental data with the help of XZ. JF wrote the manuscript, which was revised by PG. All authors read and approved the final manuscript.

\section{Ethics approval and consent to participate}

Not applicable.

\section{Patient consent for publication}

Not applicable.

\section{Competing interests}

The authors declare they have no competing interests.

\section{References}

1. Torre LA, Trabert B, DeSantis CE, Miller KD, Samimi G, Runowicz CD, Gaudet MM, Jemal A and Siegel RL: Ovarian cancer statistics, 2018. CA Cancer J Clin 68: 284-296, 2018.

2. Siegel RL, Miller KD and Jemal A: Cancer statistics, 2016. CA Cancer J Clin 66: 7-30, 2016.

3. Edwards BK, Brown ML, Wingo PA, Howe HL, Ward E, Ries LA, Schrag D, Jamison PM, Jemal A, Wu XC, et al: Annual report to the nation on the status of cancer, 1975-2002, featuring population-based trends in cancer treatment. J Natl Cancer Inst 97: 1407-1427, 2005.
4. Han C, Zhang M, Luo X, Wang C, Yin L, Pang C, Feng T, Ren Y, Wang B, Zhang L, et al: Secular trends in the prevalence of type 2 diabetes in adults in China from 1995 to 2014: A meta-analysis. J Diabetes 9: 450-461, 2017.

5. Sona MF, Myung SK, Park K and Jargalsaikhan G: Type 1 diabetes mellitus and risk of cancer: A meta-analysis of observational studies. Jpn J Clin Oncol 48: 426-433, 2018.

6. Luo J, Chen YJ and Chang LJ: Fasting blood glucose level and prognosis in non-small cell lung cancer (NSCLC) patients. Lung Cancer 76: 242-247, 2012.

7. Yu WS, Lee CY, Park SY, Suh JW, Narm KS, Kim DJ, Chung KY and Lee JG: Prognostic factors for resected non-small cell lung cancer in patients with type 2 diabetes mellitus. J Surg Oncol 117: 985-993, 2018.

8. Ji H, Liu YE, Jia T, Wang M, Liu J, Xiao G, Joseph BK, Rosen C and Shi YE: Identification of a breast cancer-specific gene, BCSG1, by direct differential cDNA sequencing. Cancer Res 57: 759-764, 1997.

9. Bruening W, Giasson BI,Klein-Szanto AJP,Lee VM,Trojanowski JQ and Godwin AK: Synucleins are expressed in the majority of breast and ovarian carcinomas and in preneoplastic lesions of the ovary. Cancer 88: 2154-2163, 2000.

10. Gu YM, Tan JX, Lu XW, Ding Y, Han X and Sun YJ: BCSG1 methylation status and BCSG1 expression in breast tissues derived from Chinese women with breast cancer. Oncology 74: 61-68, 2008.

11. Tastekin D, Kargin S, Karabulut M, Yaldız N, Tambas M, Gurdal N, Tatli AM, Arslan D, Gok AF and Aykan F: Synuclein-gamma predicts poor clinical outcome in esophageal cancer patients. Tumour Biol 35: 11871-11877, 2014.

12. Ye Q, Wang TF, Peng YF, Xie J, Feng B, Qiu MY, Li LH, Lu AG, Liu BY and Zheng MH: Expression of $\alpha-, \beta$ - and $\gamma$-synuclein in colorectal cancer, and potential clinical significance in progression of the disease. Oncol Rep 23: 429-436, 2010.

13. Liu C, Shi B, Hao C, Wang Q, Lv Q, Xing N, Shou J, Qu L, Gao Y, Qin C, et al: Urine gamma-synuclein as a biomarker for the diagnosis of bladder cancer. Oncotarget 7: 43432-43441, 2016.

14. Zheng Y, Jiang J, Zhao N, Liu R, Yang C, Zhang J, Sun M and Zhang X: Expression of $\gamma$-synuclein in non-small cell lung cancer. Zhongguo Laonianxue Zazhi 31: 4771-4773, 2011.

15. Li M, Yin Y, Hua H, Sun X, Luo T, Wang J and Jiang Y: The reciprocal regulation of $\gamma$-synuclein and IGF-I receptor expression creates a circuit that modulates IGF-I signaling. J Biol Chem 285: 30480-30488, 2010.

16. Higashi Y, Sukhanov S, Anwar A, Shai SY and Delafontaine P: Aging, atherosclerosis, and IGF-1. J Gerontol A Biol Sci Med Sci 67: 626-639, 2012.

17. $\mathrm{Xu} \mathrm{C}$ : Insulin-like growth factor type 1 receptor and malignancy:An update. Journal of Modern Oncology 23: 706-709, 2015

18. Annibalini G, Lucertini F, Agostini D, Vallorani L, Gioacchini A, Barbieri E, Guescini M, Casadei L, Passalia A, Del Sal M, et al: Concurrent aerobic and resistance training has anti-inflammatory effects and increases both plasma and leukocyte levels of IGF-1 in late middle-aged type 2 diabetic patients. Oxid Med Cell Longev 2017: 3937842, 2017.

19. Pollak M: The insulin and insulin-like growth factor receptor family in neoplasia: An update. Nat Rev Cancer 12: 159-169, 2012.

20. Ding CZ, Guo XF, Wang GL, Wang HT, Xu GH, Liu YY, Wu ZJ, Chen YH, Wang $\mathbf{J}$ and Wang WG: High glucose contributes to the proliferation and migration of non-small cell lung cancer cells via GAS5-TRIB3 axis. Biosci Rep 38: BSR20171014, 2018.

21. Zhang J, Luo W, Chi X, Zhang L, Ren Q, Wang H and Zhang W: IGF2BP1 silencing inhibits proliferation and induces apoptosis of high glucose-induced non-small cell lung cancer cells by regulating Netrin-1. Arch Biochem Biophys 693: 108581, 2020.

22. Livak KJ and Schmittgen TD: Analysis of relative gene expression data using real-time quantitative PCR and the 2(-Delta Delta C(T)) Method. Methods 25: 402-408, 2001.

23. Hemminki K, Li X, Sundquist J and Sundquist K: Risk of cancer following hospitalization for type 2 diabetes. Oncologist 15: 548-555, 2010.

24. Cheng X and Han Y: Impact of diabetes mellitus on lung cancer and its biological mechanism: A Literature Review. Chin Gen Pract 21: 1779-1784, 2018 .

25. Luo J, Hendryx M, Qi L, Ho GY and Margolis KL: Pre-existing diabetes and lung cancer prognosis. Br J Cancer 115: 76-79, 2016.

26. Zhu L, Cao H, Zhang T, Shen H, Dong W, Wang L and Du J: The effect of diabetes mellitus on lung cancer prognosis: A PRISMA-compliant meta-analysis of cohort studies. Medicine (Baltimore) 95: e3528, 2016. 
27. Renehan AG, Frystyk J and Flyvbjerg A: Obesity and cancer risk: The role of the insulin-IGF axis. Trends Endocrinol Metab 17: 328-336, 2006.

28. Papa V, Pezzino V, Costantino A, Belfiore A, Giuffrida D, Frittitta L, Vannelli GB, Brand R, Goldfine ID and Vigneri R: Elevated insulin receptor content in human breast cancer. J Clin Invest 86: 1503-1510, 1990.

29. Pollak MN, Schernhammer ES and Hankinson SE: Insulin-like growth factors and neoplasia. Nat Rev Cancer 4: 505-518, 2004.

30. Giovannucci E, Harlan DM, Archer MC, Bergenstal RM, Gapstur SM, Habel LA, Pollak M, Regensteiner JG and Yee D: Diabetes and cancer: A consensus report. Diabetes Care 33: $1674-1685,2010$

31. Li F, Liu Y, Ren L, Sun Q and Luo YX: IGF-1 regulates Ang II and VEGF signaling pathways in retinal neovascularization. Eur Rev Med Pharmacol Sci 22: 6175-6180, 2018.

32. Surgucheva IG, Sivak JM, Fini ME, Palazzo RE and Surguchov AP: Effect of gamma-synuclein overexpression on matrix metalloproteinases in retinoblastoma Y79 cells. Arch Biochem Biophys 410: 167-176, 2003.

33. Jiang Y, Liu YE, Goldberg ID and Shi YE: $\gamma$ synuclein, a novel heat-shock protein-associated chaperone, stimulates ligand-dependent estrogen receptor $\alpha$ signaling and mammary tumorigenesis. Cancer Res 64: 4539-4546, 2004.

34. Shen P-H, Fan Q-X, Li Y-W, Zhang W, He XK, Wang Z and Zhang YH: SNCG shRNA suppressed breast cancer cell xenograft formation and growth in nude mice. Chin Med J (Engl) 124: 1524-1528, 2011.

35. Alexa A, Gógl G, Glatz G, Garai Á, Zeke A, Varga J, Dudás E, Jeszenői N, Bodor A, Hetényi C, et al: Structural assembly of the signaling competent ERK2-RSK1 heterodimeric protein kinase complex. Proc Natl Acad Sci USA 112: 2711-2716, 2015.
36. Liu K, Lu R, Zhao Q, Du J, Li Y, Zheng M and Zhang S: Association and clinicopathologic significance of p38MAPKERK-JNK-CDC25C with polyploid giant cancer cell formation. Med Oncol 37: 6, 2019.

37. Yang T, Wang Y, Zhan S, Jia Q and Wang X: Effects of ERK gene overexpression on proliferation, migration and invasion of lung cancer A549 Cells. J Ningxia Med Univ 42: 332-338, 2020.

38. Eisinger-Mathason TSK, Andrade $\mathrm{J}$ and Lannigan DA: RSK in tumorigenesis: Connections to steroid signaling. Steroids 75: 191-202, 2010

39. Jian W, Xue-zhong H, Jing L and Jing G: The molecular mechanism of miR23a promotes apoptosis of lung cancer cell line A549 Caspase-3 expression. Anat Res 40: 494-497, 2018.

40. Fan C, Liu J, Tian J, Zhang Y, Yan M and Zhu C: siRNA Targeting of the SNCG gene inhibits the growth of gastric carcinoma SGC7901 cells in vitro and in vivo by downregulating the phosphorylation of AKT/ERK. Cytogenet Genome Res 154: 209-216, 2018.

41. Man GCW, Wang J, Song Y, Wong JH, Zhao Y, Lau TS Leung KT, Chan TH, Wang H, Kwong J, et al: Therapeutic potential of a novel prodrug of green tea extract in induction of apoptosis via ERK/JNK and Akt signaling pathway in human endometrial cancer. BMC Cancer 20: 964, 2020.

This work is licensed under a Creative Commons Attribution-NonCommercial-NoDerivatives 4.0 International (CC BY-NC-ND 4.0) License. 